\title{
The Intention to Receive the COVID-19 Vaccine in China: Insights from Protection Motivation Theory
}

\author{
$\mathrm{Lu} \mathrm{Li}^{1}{ }^{1}$, Jian Wang ${ }^{2,3}$, Stephen Nicholas ${ }^{4,5,6,7}$, , Elizabeth Maitland ${ }^{8}$, Anli Leng ${ }^{9}$ and Rugang Liu ${ }^{10,11, *(\mathbb{D})}$ \\ 1 School of Business Administration, Jiangsu Vocational Institute of Commerce, Nanjing 211168, China; \\ 200015@jvic.edu.cn \\ 2 Dong Fureng Economic and Social Development School, Wuhan University, Beijing 100010, China; \\ wangjian993@whu.edu.cn \\ 3 Center for Health Economics and Management at School of Economics and Management, Wuhan University, \\ Wuhan 430072, China \\ 4 Australian National Institute of Management and Commerce, Eveleigh, Sydney, NSW 2015, Australia; \\ stephen.nicholas@newcastle.edu.au \\ 5 Research Institute for International Strategies, Guangdong University of Foreign Studies, \\ Guangzhou 510420, China \\ 6 School of Economics and School of Management, Tianjin Normal University, Tianjin 300074, China \\ 7 Newcastle Business School, University of Newcastle, Newcastle, NSW 2308, Australia \\ 8 School of Management, University of Liverpool, Chatham Building, Chatham Street, Liverpool L697ZH, UK; \\ e.maitland@liverpool.ac.uk \\ 9 School of Political Science and Public Administration, Institute of Governance, Shandong University, \\ Qingdao 266237, China; lenganli@sdu.edu.cn \\ 10 School of Health Policy \& Management, Nanjing Medical University, Nanjing 211166, China \\ 11 Center for Global Health, Nanjing Medical University, Nanjing 211166, China \\ * Correspondence: rugangliu@njmu.edu.cn
}

Citation: Li, L.; Wang, J.; Nicholas, S.; Maitland, E.; Leng, A.; Liu, R. The Intention to Receive the COVID-19 Vaccine in China: Insights from Protection Motivation Theory. Vaccines 2021, 9, 445. https:// doi.org/10.3390/vaccines 9050445

Academic Editors: Tiziana Ramaci and Massimiliano Barattucci

Received: 27 March 2021

Accepted: 29 April 2021

Published: 2 May 2021

Publisher's Note: MDPI stays neutral with regard to jurisdictional claims in published maps and institutional affiliations.

Copyright: (c) 2021 by the authors. Licensee MDPI, Basel, Switzerland. This article is an open access article distributed under the terms and conditions of the Creative Commons Attribution (CC BY) license (https:// creativecommons.org/licenses/by/ $4.0 /)$.
Abstract: (1) Background: More coronavirus disease 2019 (COVID-19) vaccines are gradually being developed and marketed. Improving the vaccination intention will be the key to increasing the vaccination rate in the future; (2) Methods: A self-designed questionnaire was used to collect data on COVID-19 vaccination intentions, protection motivation and control variables. Pearson Chi-square test and multivariate ordered logistic regression models were specified to analyze the determinants of intention to receive COVID-19 vaccine; (3) Results: Although the vaccine was free, $17.75 \%$ of the 2377 respondents did not want, or were hesitant, to receive the COVID-19 vaccine. Respondents' cognition of vaccine safety, external reward and response efficacy were positively related to COVID19 vaccination intention, while age, income and response cost were negatively related to the intention to receive the COVID-19 vaccine. Professionals and people without medical insurance had the lowest intention to vaccinate; (4) Conclusions: The older aged, people without health insurance, those with higher incomes and professionals should be treated as the key intervention targets. Strengthening publicity and education about the safety and efficacy of COVID-19 vaccines, training vaccinated people and community leaders as propagandists for the vaccine, and improving the accessibility to the COVID-19 vaccine are recommended to improve COVID-19 vaccination intention.

Keywords: protection motivation theory; COVID-19; vaccination; intention; determinant

\section{Introduction}

Corona Virus Disease 2019 (COVID-19) may be one of the most serious infectious diseases in human history, with over 119.2 million infected cases, and over 3 million deaths reported by World Health Organization as of 15 April 2021 [1]. COVID-19 vaccination programs covering the entire population will be the main way that countries control and prevent COVID-19. Vaccine hesitancy presents the major challenge for national vaccination campaigns, but the intention to COVID-19 vaccinate is poorly understood. High vaccine hesitancy rates, ranging from $14 \%$ to $30 \%$ have been variously reported in the United 
States of America [2], France [3], Japan [4], Canada [5] and the United Kingdom [6,7]. Even among healthcare professionals (HCP), the hesitancy rate for COVID-19 vaccinate has been reported at $24 \%$ in France, with only $64.4 \%$ HCP in Greece and $34.9 \%$ in the Republic of Cyprus intending to vaccinate [8,9]. Utilizing protection motivation theory (PMT), this paper analyzes the intention to COVID-19 vaccinate in China. PMT provides a widely used analytical framework to identify the determinants of vaccination behavior and vaccination willingness [10-21]. By providing a comprehensive theoretical framework on vaccination intentions, the paper not only reveals the factors determining the intention to vaccinate in China, but also informs policy makers on how to structure effective COVID-19 information campaigns to maximize the vaccine take-up.

Developed by Rogers in 1975 [22], protection motivation theory (PMT) argues that individuals are motivated to react in a self-protected way to perceived health threats. As shown in Figure 1, based on information, such as the environmental context and individual characteristics, the protection motivation decision involves two appraisal processes: threat appraisal and coping appraisal [22]. Threat appraisal depends on the individuals' cognition of the threat, including the severity of the threat, one's vulnerability, internal rewards and external rewards. Severity refers to people's cognition of the magnitude of the harm caused by health hazards, such as COVID-19; vulnerability refers to individual's perception of the possibility of suffering harm when they exposed to the health threat, such as the possibility of catching COVID-19; internal rewards refers to individual's self-satisfaction after taking an action to protect from the health threat; external rewards refers to cost-benefit factors external to the individual, such as family, friends and the wider society of taking harm reduction through, for example, the COVID-19 vaccination [22]. The coping appraisal process evaluates an individual's ability to cope with and avert the threatened health danger through self-efficacy, response efficacy and response cost [23]. Self-efficacy is the belief that one is, or is not, capable of harm reduction action, such as taking the COVID-19 vaccine [24]; response efficacy refers to one's belief that taking a harm reduction action, such as COVID-19 vaccination, will be effective in health harm reduction; response cost are the barriers to taking protective behavior, measured by vaccine costs, vaccination knowledge and side-effect concerns.

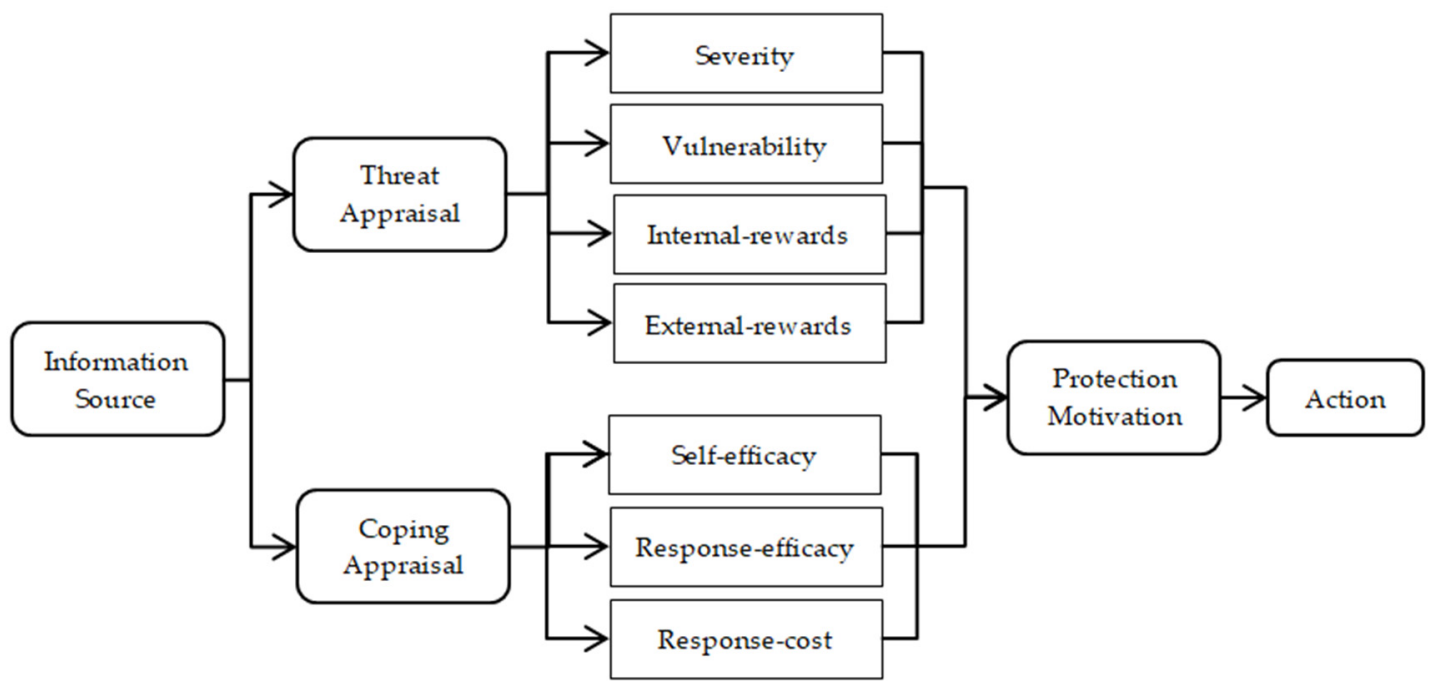

Figure 1. Protection motivation theory.

PMT has been shown to be a powerful framework for behavior interpretation, intervention and prediction research on health harm reduction in China, the United States, Thailand, New Zealand, and Australia [10-14]. It has also been widely used to analyze the determinants of vaccination behavior and vaccination willingness [15-17]. For example, analyzing hepatitis B virus (HBV) vaccination behavior and willingness of Chinese migrant workers, Liu et al. found that vulnerability and response efficacy were significant deter- 
minants of $\mathrm{HBV}$ vaccination behavior, and vulnerability and self-efficacy were significant determinants of HBV vaccination willingness [18]. Among migrant workers in Tianjin, Liu et al. found that severity and self-efficacy were positively, and response cost negatively, related to HBV vaccination intention [19]. Ling et al. (2019) analyzed the intention to receive the seasonal influenza vaccine among 547 residents in the United States, and found that severity, susceptibility, the maladaptive response reward, self-efficacy, and response efficacy were unique determinants of vaccination intention, and the PMT factors explained $62 \%$ of the variance in intention to vaccinate [20]. A study in Switzerland showed that response efficacy was directly related to parents' intention to adhere to measles, mumps and rubella (MMR) vaccination recommendations among parents of middle school students aged 13-15 [21]. Ling et al. used the PMT to predict the intention to receive the seasonal influenza vaccine, and found that severity of and susceptibility to influenza, the perceived benefits of not vaccinating, the self-efficacy to vaccinate, and the response efficacy were significant predictors of intention and the PMT variables accounted for $62 \%$ of the variance [20].

There has been a small number of COVID-19 PMT studies, including 734 healthcare workers in Iran [25], 649 Filipinos answering an online questionnaire [26], and 3145 students from 43 universities in China [27]. The online survey of Chinese students found that the perceived severity of COVID-19 was positively associated with motivation to have COVID19 vaccination and receiving COVID-19 information from medical personnel was associated with greater self-efficacy, response efficacy, and knowledge, whereas receiving information concerning COVID-19 vaccination from coworkers/colleagues was associated with less response efficacy and knowledge. Although PMT has been proved to be a robust analytical framework to predict the vaccination intention and its determinants, there has been no nationwide study using PMT to analyze the determinant of residents' intention to receive the COVID-19 vaccine in China. Covering all occupations, rural-urban and geographic regions, age, sex, income, education level and specifying a full PMT model, this paper analyzes factors determining the intention to vaccinate in China.

\section{Materials and Methods}

\subsection{Sampling Method}

Based on previous related research [18], a questionnaire was designed to collect information on COVID-19 vaccination intentions, PMT factors and control variables, such as age, sex, occupation and health. Nine provinces were selected randomly from China's 27 provinces, with equal numbers from the eastern, central and western region and equal numbers of low, medium and high GDP based on based on each province's 2019 GDP. Three cities were selected randomly from each province according to their 2019 GDP rank. All investigators were recruited from local colleges or universities and they received standardized training before commencing the investigation. Snowball sampling was applied with 100 participants interviewed face-to-face (or through online video for respondents required to home quarantine) in each city. The investigators were asked to choose respondents with equal numbers of males and females and urban and rural residents in a 3:2 ratio to reflect the national urban-rural distribution. The survey was conducted during the first two weeks of June 2020. All respondents were informed about the survey purpose and signed the informed consent form before the interview. A total of 2700 adults aged over 18 years old were interviewed. After deleting invalid cases with missing data, the final sample of 2377 respondents represented an $88.04 \%$ response rate.

\subsection{Measurement of Intention to Receive COVID-19 Vaccine}

The Chinese government has made the COVID-19 vaccine free, with high risk individuals receiving the vaccine first [28]. As of April 2021, over 190 million Chinese have received the same COVID-19 vaccine, with only $0.002 \%$ serious adverse reactions reported in Hong Kong and similar rates in mainland China [29]. The intention to receive the COVID-19 vaccine was measured by a one-item question: "Would you like to receive the 
COVID-19 vaccine if the vaccine is free?" with three answers, "No" (0), "it depends" (1) and

"Yes" (2) representing the COVID-19 vaccination intention from low to high commitment.

\subsection{Measurement of PMT Factors}

Table 1 shows the one-item question to measure each PMT factor, with respondents replying on a three-point scale: "disagree" (0), "neutral" (1) and "agree" (2).

Table 1. Measurement of PMT factors.

\begin{tabular}{|c|c|c|}
\hline Factors & Description & Assignment \\
\hline Severity & COVID-19 is a serious disease. & Disagree $=0 ;$ Neutral $=1 ;$ Agree $=2$ \\
\hline Vulnerability & $\begin{array}{l}\text { My relatives, friends and I face the risk of } \\
\text { COVID-19 infection. }\end{array}$ & Disagree $=0 ;$ Neutral $=1 ;$ Agree $=2$ \\
\hline Internal reward & $\begin{array}{l}\text { After I received the COVID-19 vaccine, I will no longer } \\
\text { be restricted in my travel. }\end{array}$ & Disagree $=0 ;$ Neutral $=1 ;$ Agree $=2$ \\
\hline External reward & $\begin{array}{l}\text { My relatives, friends and people around me all want to } \\
\text { get vaccinated against COVID-19. }\end{array}$ & Disagree $=0 ;$ Neutral $=1 ;$ Agree $=2$ \\
\hline Self-efficacy & $\begin{array}{l}\text { I believe I will have the ability to get the COVID-19 } \\
\text { vaccine in the future. }\end{array}$ & Disagree $=0 ;$ Neutral $=1 ;$ Agree $=2$ \\
\hline Response efficacy & The COVID-19 vaccine is effective against COVID- 19. & Disagree $=0 ;$ Neutral $=1 ;$ Agree $=2$ \\
\hline Response cost & $\begin{array}{c}\text { Going to get the COVID-19 vaccine would waste my } \\
\text { time or delay my work. }\end{array}$ & Disagree $=0 ;$ Neutral $=1 ;$ Agree $=2$ \\
\hline
\end{tabular}

\subsection{Measurement of Control Variables}

The control variables included sex, age groups, average monthly income groups, education level, occupation, medical insurance, urban or rural residence, self-rated health level, east-west-central region, and respondents' awareness of COVID-19 vaccine efficacy, safety and infection risk. Occupations were categorized into professionals (including physicians, teachers and civil servants), farmers, migrant workers, self-employed, unemployed, students, the retired and other. Self-rated health level was classified into, "bad", "medium" and "good", based on the question: "How is your health status compared to your peers?" A single-choice question was used to measure respondents' awareness of vaccine safety, "Do you believe COVID-19 vaccine is safe?", and coded "don't agree-low safety", "neutral attitude—-medium safety" and "agree—high safety".

\subsection{Statistical Analyses}

The database was built by using software EpiData 3.1 (The EpiData Association, Denmark), with all data double-entered and checked for consistency, and STATA 12.0 (StataCorp., College Station, Texas TX, USA) used for statistical analysis. Pearson chisquare test was used to compare the differences in COVID-19 vaccination intentions among subgroups and multivariate ordered logistic regression models, and the odds ratio (OR), were used to assess the associations between each independent variable and the COVID-19 vaccination intention. The underlying hypothesis of the study is that the control variables and PMT factors had significant influence $(p<0.05)$ on participants' COVID-19 vaccination intention.

\section{Results}

\subsection{Statistical Description of Respondents' Characteristics and PMT Factors}

Table 2 displays the characteristics of 2377 participants. The median age was 35 years old; broadly equal number of males (48.55\%) and females (51.45\%); the ratio of urban $(61.51 \%)$ and rural $(38.49 \%)$ respondents close to the Chinese national urban-rural 3:2 ratio. The median monthly income was RMB 5000, with the percentage in each income group broadly equal. Roughly two-thirds (61.93\%) of respondents had a below high school education level; $29.9 \%$ were professionals, $26.88 \%$ students, $12.16 \%$ migrant workers; $96.93 \%$ of participants reported their self-rated health as "medium or good"; only $3.7 \%$ had 
no medical insurance; the distribution across eastern (31.47\%) central (28.86\%) and western $(39.67 \%)$ regions were roughly equal. Most participants believed the COVID-19 vaccine was safe at a medium or high level $(82.41 \%)$ and overwhelmingly agreed that COVID-19 was a serious disease $(91.67 \%)$. A quarter of respondents believed that they, their relatives and friends could be infected by COVID-19; $46.87 \%$ believed that they would not be restricted in their travel by COVID-19 after receiving the vaccine; $63.4 \%$ believed their relatives and friends would receive COVID-19 vaccine. Most respondents believed that they had the ability to receive the COVID-19 vaccine (77.96\%) and that the COVID-19 vaccine would be effective against COVID-19 (86.62\%). Only 14.51\% believed going to receive the COVID-19 vaccine would waste time and delay their work. As shown in Figure 2, 82.25\% intended to receive the COVID-19 vaccine, but $14.05 \%$ were hesitant to vaccinate and $3.7 \%$ did not want to get vaccinated.

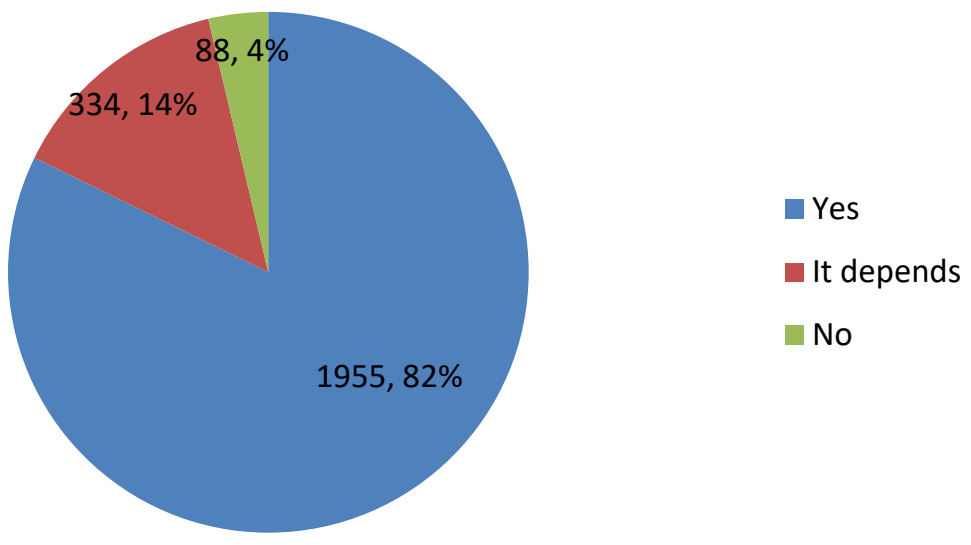

Figure 2. Overall percentage of intention to receive COVID-19 vaccine (number, percentage).

Table 2. PMT factors and control variables.

\begin{tabular}{|c|c|c|c|c|c|c|c|c|c|c|c|c|}
\hline & \multirow{2}{*}{ Variables } & & \multicolumn{2}{|c|}{ Total } & \multicolumn{2}{|c|}{ No } & \multicolumn{2}{|c|}{ It Depends } & \multicolumn{2}{|c|}{ Yes } & \multirow{2}{*}{$x^{2}$} & \multirow{2}{*}{$p$} \\
\hline & & & $\mathbf{N}$ & $\%$ & $\mathbf{N}$ & $\%$ & $\mathbf{N}$ & $\%$ & $\mathbf{N}$ & $\%$ & & \\
\hline \multirow{21}{*}{$\begin{array}{l}\text { PMT } \\
\text { factors }\end{array}$} & \multirow[t]{3}{*}{ Severity } & Disagree & 46 & 1.94 & 6 & 13.04 & 4 & 8.70 & 36 & 78.26 & 28.303 & $<0.001$ \\
\hline & & Neutral & 152 & 6.39 & 6 & 3.95 & 38 & 25.00 & 108 & 71.05 & & \\
\hline & & Agree & 2179 & 91.67 & 76 & 3.49 & 292 & 13.40 & 1811 & 83.11 & & \\
\hline & \multirow[t]{3}{*}{ Vulnerability } & Disagree & 1107 & 46.57 & 50 & 4.52 & 143 & 12.92 & 914 & 82.57 & 12.692 & 0.013 \\
\hline & & Neutral & 670 & 28.19 & 18 & 2.69 & 117 & 17.46 & 535 & 79.85 & & \\
\hline & & Agree & 600 & 25.24 & 20 & 3.33 & 74 & 12.33 & 506 & 84.33 & & \\
\hline & \multirow[t]{3}{*}{ Internal rewards } & Disagree & 489 & 20.57 & 22 & 4.50 & 74 & 15.13 & 393 & 80.37 & 39.773 & $<0.001$ \\
\hline & & Neutral & 774 & 32.56 & 33 & 4.26 & 150 & 19.38 & 591 & 76.36 & & \\
\hline & & Agree & 1114 & 46.87 & 33 & 2.96 & 110 & 9.87 & 971 & 87.16 & & \\
\hline & \multirow[t]{3}{*}{ External rewards } & Disagree & 141 & 5.93 & 14 & 9.93 & 36 & 25.53 & 91 & 64.54 & 209.583 & $<0.001$ \\
\hline & & Neutral & 729 & 30.67 & 46 & 6.31 & 187 & 25.65 & 496 & 68.04 & & \\
\hline & & Agree & 1507 & 63.40 & 28 & 1.86 & 111 & 7.37 & 1368 & 90.78 & & \\
\hline & \multirow[t]{3}{*}{ Self-efficacy } & Disagree & 87 & 3.66 & 7 & 8.05 & 13 & 14.94 & 67 & 77.01 & 66.452 & $<0.001$ \\
\hline & & Neutral & 437 & 18.38 & 26 & 5.95 & 107 & 24.49 & 304 & 69.57 & & \\
\hline & & Agree & 1853 & 77.96 & 55 & 2.97 & 214 & 11.55 & 1584 & 85.48 & & \\
\hline & \multirow[t]{3}{*}{ Response efficacy } & Disagree & 17 & 0.72 & 6 & 35.29 & 4 & 23.53 & 7 & 41.18 & 245.711 & $<0.001$ \\
\hline & & Neutral & 301 & 12.66 & 28 & 9.30 & 111 & 36.88 & 162 & 53.82 & & \\
\hline & & Agree & 2059 & 86.62 & 54 & 2.62 & 219 & 10.64 & 1786 & 86.74 & & \\
\hline & \multirow[t]{3}{*}{ Response cost } & Disagree & 1500 & 63.10 & 52 & 3.47 & 166 & 11.07 & 1282 & 85.47 & 40.708 & $<0.001$ \\
\hline & & Neutral & 532 & 22.38 & 20 & 3.76 & 117 & 21.99 & 395 & 74.25 & & \\
\hline & & Agree & 345 & 14.51 & 16 & 4.64 & 51 & 14.78 & 278 & 80.58 & & \\
\hline
\end{tabular}


Table 2. Cont.

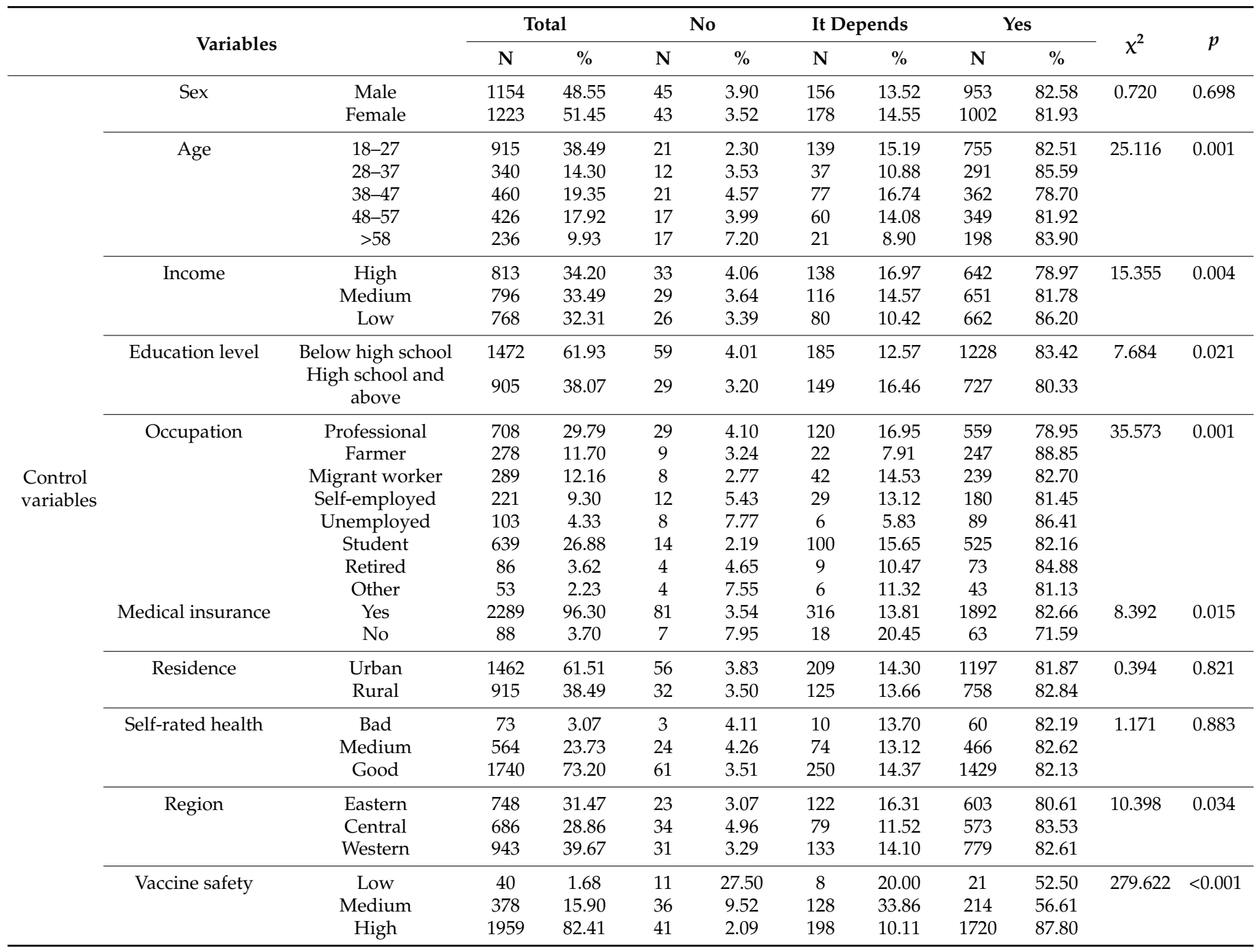

\subsection{Results of Pearson Chi-Square Test}

Table 2 illustrates the intention to receive COVID-19 vaccine by subgroups. The percentage of people who did not want the COVID-19 vaccine was highest in the over 58 years old group $(7.2 \%)$ and lowest in the $18-27$ years old group $(2.3 \%)(p=0.001)$. The COVID-19 vaccination intention rate decreased with rising income, with the lowest vaccination intention in the highest income group $(78.97 \%)(p=0.004)$. Respondents with the lowest education level (lower than high school education) had a significantly higher intention $(83.42 \%)$ to receive the COVID-19 vaccine than respondents who had a high school and above education $(80.33 \%, p=0.021)$. Among all occupations, professionals had the lowest intention (78.95\%) and farmers had the highest intention (88.85\%) to COVID-19 vaccinate $(p=0.001)$. The respondents who had medical insurance $(82.66 \%)$ had a higher intention of vaccinating than the noninsured respondents $(71.59 \%, p=0.015)$. Respondents from the central region $(83.53 \%$ ) had the highest intention to revive the COVID-19 vaccine, followed by the western area $(82.61 \%)$ and then the more affluent eastern area $(80.61 \%$, $p=0.034)$. The vaccination intention increased significantly with participants' increased awareness of vaccine safety $(p<0.001)$.

There were significant differences across all PMT subgroups $(p<0.05)$. The percentage of respondents who did not want to receive COVID-19 vaccine decreased with an increased level of severity, internal reward, external reward, self-efficacy and response efficacy, but increased with increased response cost level $(p<0.001)$. Those participants who agreed that 
they and people around them might get COVID-19 in the future had the highest intention to receive the COVID-19 vaccine (84.33\%), followed by the disagree group $(82.57 \%)$ and neutral group $(79.85 \%)(p=0.013)$.

\subsection{Results of Multivariate Ordered Logistic Regressions}

Table 3 shows the results of multivariate ordered logistic regression models, specified to analyze the relationship between intention to receive the COVID-19 vaccine and the independent variables. The independent variables in Model 1 comprised only the control variables, while Model 2 specified both the PMT factors and the control variables. The value of $\log$ likelihood and pseudo $\mathrm{R}^{2}$ in Model 2 (Log likelihood $=-1116.2274$, Pseudo $\left.R^{2}=0.1592\right)$ were lager than that in Model 1 (Log likelihood $=-1203.4388$, Pseudo $\left.\mathrm{R}^{2}=0.0935\right)$, so Model 2, with the PMT factors, performed better at explaining the intention to receive the COVID-19 vaccine.

Among the control variables, sex, education level, urban-rural residence, self-rated health and region had no influence on respondents' intention to receive the COVID-19 vaccine $(p>0.05)$. Respondents in all age groups, except those $28-37$ age years old, had a higher intention to receive COVID-19 vaccine than the 18-27 age group, and the intention to vaccinate decreased as age increased $(\mathrm{OR}=0.637$ (age 38-47), OR $=0.594$ (age 48-57), $\mathrm{OR}=0.471$ (age 58+), $p<0.05)$. Respondents in the low income group had a higher intention to vaccinate than the high income group $(\mathrm{OR}=1.705, p=0.002)$; farmers had a higher intention to receive the COVID-19 vaccine than professionals (OR $=2.134, p=0.005)$; those without medical insurance had a lower COVID-19 vaccination intention than the insured ( $\mathrm{OR}=0.584, p=0.049)$. The intention to vaccinate was higher by respondents who perceived the COVID-19 vaccine had high safety than respondents who perceived the vaccine had a low safety $(\mathrm{OR}=0.546, p<0.001)$.

Among the PMT variables in Model 2, severity, vulnerability, internal reward and self-efficacy had no influence on respondents' intention to receive the COVID-19 vaccine $(p>0.05)$. There was a significant association between intention to receive the COVID-19 vaccine and external reward, response efficacy and response cost $(p<0.05)$. The respondents who agree with the external reward description were more likely to receive the COVID-19 vaccine than respondents who disagree $(\mathrm{OR}=4.519, p<0.001)$. The vaccination intention increased as response efficacy increased (neutral: $\mathrm{OR}=3.105, p=0.041$; agree: $\mathrm{OR}=5.768$, $p=0.001$ ), but deceased as response cost increased (neutral: $\mathrm{OR}=0.749, p=0.047$; agree: $\mathrm{OR}=0.5, p<0.001)$.

Table 3. Multiple ordered logistic regression models.

\begin{tabular}{|c|c|c|c|c|c|c|c|c|c|c|}
\hline & \multirow{2}{*}{ Variables } & & \multicolumn{4}{|c|}{ Model 1} & \multicolumn{4}{|c|}{ Model 2} \\
\hline & & & $\beta$ & S.E. & $p$ & OR $(95 \% C I)$ & $\beta$ & S.E. & $p$ & OR $(95 \% C I)$ \\
\hline \multirow{21}{*}{$\begin{array}{l}\text { PMT } \\
\text { factors }\end{array}$} & Severity & Disagree & & & & & \multicolumn{4}{|c|}{ (Reference group) } \\
\hline & & Neutral & & & & & 0.681 & 0.45 & 0.130 & $1.976(0.819,4.767)$ \\
\hline & & Agree & & & & & 0.674 & 0.40 & 0.090 & $1.962(0.900,4.276)$ \\
\hline & Vulnerability & Disagree & & & & & \multicolumn{4}{|c|}{ (Reference group) } \\
\hline & & Neutral & & & & & 0.161 & 0.15 & 0.269 & $1.175(0.883,1.565)$ \\
\hline & & Agree & & & & & -0.073 & 0.15 & 0.637 & $0.930(0.686,1.259)$ \\
\hline & Internal rewards & Disagree & & & & & \multicolumn{4}{|c|}{ (Reference group) } \\
\hline & & Neutral & & & & & 0.171 & 0.17 & 0.300 & $1.186(0.859,1.640)$ \\
\hline & & Agree & & & & & 0.006 & 0.17 & 0.973 & $1.006(0.725,1.394)$ \\
\hline & External rewards & Disagree & & & & & \multicolumn{4}{|c|}{ (Reference group) } \\
\hline & & Neutral & & & & & 0.192 & 0.21 & 0.364 & $1.211(0.801,1.831)$ \\
\hline & & Agree & & & & & 1.508 & 0.22 & $<0.001$ & $4.519(2.914,7.009)$ \\
\hline & Self-efficacy & Disagree & & & & & \multicolumn{4}{|c|}{ (Reference group) } \\
\hline & & Neutral & & & & & -0.309 & 0.32 & $0.330^{\circ}$ & $0.734(0.394,1.367)$ \\
\hline & & Agree & & & & & -0.008 & 0.30 & 0.979 & $0.992(0.547,1.798)$ \\
\hline & Response efficacy & Disagree & & & & & \multicolumn{4}{|c|}{ (Reference group) } \\
\hline & & Neutral & & & & & 1.133 & 0.55 & $0.041^{\circ}$ & $3.105(1.048,9.197)$ \\
\hline & & Agree & & & & & 1.752 & 0.55 & 0.001 & $5.768(1.956,17.010)$ \\
\hline & Reaction cost & Disagree & & & & & \multicolumn{4}{|c|}{ (Reference group) } \\
\hline & & Neutral & & & & & -0.288 & 0.15 & $0.047^{\circ}$ & $0.749(0.564,0.996)$ \\
\hline & & Agree & & & & & -0.694 & 0.18 & $<0.001$ & $0.500(0.354,0.705)$ \\
\hline
\end{tabular}


Table 3. Cont.

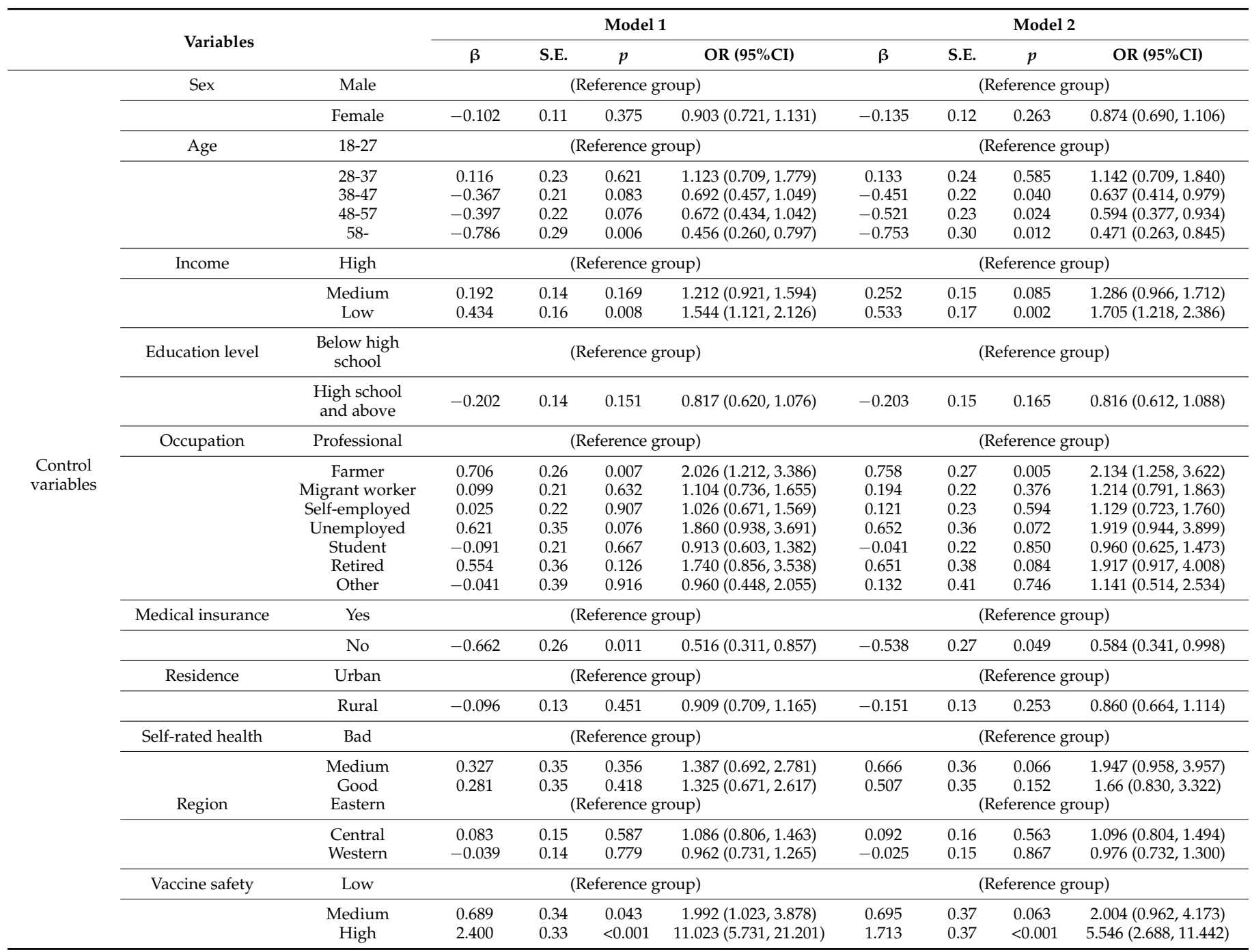

\section{Discussion}

Based on protection motivation theory, the intention to receive the COVID-19 vaccine and its influencing factors were analyzed. The outcomes can guide COVID-19 vaccine uptake and shape vaccination policy. The COVID-19 vaccination intention rate was $82.25 \%$, but $17.75 \%$ of respondents did not want, or hesitated, to receive the free COVID-19 vaccine. The vaccination intention rate was higher than that reported in Hong Kong (from 34.8\% to $44.2 \%)$ and in an online survey in China (54.6\%) [30,31]. Lower COVID-19 vaccination rates also were reported in other Asian countries with $65.7 \%$ of participants indicating a willingness to be vaccinated against COVID-19 in Japan [4], 53.1\% in Kuwait [32], 78.3\% in Indonesia [33] and 64.7\% in Saudi Arabia [34]. A multi-country survey in Europe showed on average 73.9\% respondents from Germany, the United Kingdom, Denmark, the Netherlands, France, Portugal and Italy were willing to receive the COVID-19 vaccine. In North America, over half of Canadians were very likely (57.5\%) to get a COVID-19 vaccine when it becomes available and $19.0 \%$ reported that they were somewhat likely to get vaccinated [5]. A online survey in the United States showed that $69 \%$ of participants intent to get vaccinated against COVID-19 [35]. In South America, 90.6\% of participants indicated they were willing to pay for a COVID-19 vaccine in Chile [36], and a survey in Ecuador showed that at least $97 \%$ of individuals were willing to accept a COVID-19 vaccine, and at least $85 \%$ were willing to pay for that vaccine [37]. In Australia, $85.8 \%$ of 
respondents would get the COVID-19 vaccine [38], but in the Congo only $27.7 \%$ of health care workers said that they would accept a COVID-19 vaccine [39].

Age, income, occupation, medical insurance, vaccine safety, external reward, response efficacy and response cost were significant influencing factors of the intention to receive the COVID-19 vaccine. Sex, education level, urban-rural residence, self-rated health, region, severity, vulnerability, internal reward and self-efficacy were not significant factors in the intention to vaccinate.

For the agree to vaccinate group, the most important determinants to vaccinate was PMT response efficacy $(\mathrm{OR}=5.768)$, followed by vaccine safety $(\mathrm{OR}=5.546$ for the high safety level group) and external reward ( $\mathrm{OR}=4.519$ for the agree group). These results were consistent with previous studies which found respondents' perception of the potential risk and harm of the COVID-19 vaccine decreased the intention to get vaccinated [32,35], while the perceived effectiveness of the vaccine increased vaccination intention [30,40-42]. Previous research on HBV [43], MMR [21] and seasonal influenza [20] vaccination intentions also found that response efficacy was a unique determinant of vaccination intention. To increase the vaccination rate, a publicity and education campaign about the safety and efficacy of COVID-19 vaccines would strength public trust in COVID-19 vaccines, increasing vaccination intentions [44-46]. Since urban-rural residence and region had no influence on respondents' vaccination intention, education campaigns should be national. News, even negative news, about COVID-19 vaccines should be reported accurately, not exaggerated or sensationalized. External reward indicated that respondents' intention to receive the COVID-19 vaccine was influenced by the viewpoint of family members, relatives and friends. We recommend using respected members of the community, such as community leaders or professionals, as well as vaccinated people, as propagandists for vaccinations to influence the population to vaccinate. Response cost indicated that the increased cost of vaccination, such as lost work time and travel time, decreased the intention to get COVID-19 vaccinated. This finding was similar to previous studies of HBV vaccination intention, which found that response cost was negatively related to intention to receive the HBV vaccine [19]. We recommended that improving the accessibility to the COVID-19 vaccinate to increase the population's vaccination intention, such as increasing the number of vaccination sites to reduce commuting time.

Even though the COVID-19 vaccine was free, the intention to COVID-19 vaccinate for respondents without medical insurance was only half those with medical insurance. Other COVID-19 research also found that vaccine acceptance was higher among the U.S. private or public health insured than those without health insurance [35]. The effect of age, income and occupation on intention to COVID-19 vaccinate was different from other studies. We found that the intention to COVID-19 vaccinate decreased with age, except for the 28-37 years old age group. In contrast, Japanese and U.S. studies found that the older age respondents had a higher intention to COVID-19 vaccinate than younger people [4,47]. In part, this can be explained by the evidence that the likelihood of COVID-19 infection and mortality from COVID-19 increased with age [48], so measures need to be implemented to increase the COVID-19 vaccination intention of the older aged. Our model showed that professionals had the lowest intention to COVID-19 vaccinate, while farmers had the highest vaccination intention. Additionally, different from other studies [33,37,49] was that respondents with lower income had a higher intention to receive COVID-19 vaccine than respondents in the high income group. The different effect of income and occupation on COVID-19 vaccination intention might reflect that the COVID-19 vaccination was free. Respondents with lower socioeconomic status are more sensitive to vaccination cost, so are more willing to vaccinate. We recommend that the older aged, people without health insurance, those with higher incomes and professionals should be the key intervention targets to improve vaccination intentions. 


\section{Strengths and Limitations}

The strengths of this study are as follows. First, we used PMT, which provides a robust, well-tested and full model to explain the cognitive mediation process of behavioral change in terms of threat and coping appraisal. In a nationwide study, our PMT model analyzed the determinants of intention to receive the COVID-19 vaccine with all seven PMT factors included. Second, COVID-19 vaccination intentions were analyzed under China's free vaccine context. Third, the data were collected from the eastern, central and western regions as well as rural and urban areas. Lastly, respondents were interviewed face-to-face or through online video, which enhanced data accuracy compared to online questionnaire surveys.

There are two major limitations. First, only one question was set to evaluate respondents' intention to receive the COVID-19 vaccine and each PMT factor. A more complex measurement method for PMT factors should be developed in further studies. Second, future studies should collect larger datasets.

\section{Conclusions}

Our PMT model found that $18 \%$ of respondents did not want, or were hesitated to get, the free COVID-19 vaccination. There were significant correlations between key control variables (age, income, occupation, medical insurance, and vaccine safety), PMT factors (external reward, response efficacy and response cost) and respondents' intention to COVID19 vaccinate. Perception of the vaccine's safety, external reward and response efficacy were positively related to COVID-19 vaccination intention, while age, income and response cost were negatively related to the intention to receive the COVID-19 vaccine. Professionals had the lowest COVID-19 vaccination intention among all occupations, and people without medical insurance had a lower intention to vaccinate than those with medical insurance. When the COVID-19 vaccine is free, strengthening publicity and education about the safety and efficacy of COVID-19 vaccines, for example using vaccinated respected leaders as propagandists, and improving the accessibility to COVID-19 vaccination centers are recommended actions to improve COVID-19 vaccination intentions. The older aged, people without health insurance, those with higher incomes and professionals should be the key intervention targets.

Author Contributions: Conceptualization, R.L. and L.L. and J.W.; methodology, R.L. and L.L.; software, R.L. and L.L.; validation, S.N. and J.W. and R.L.; formal analysis, R.L. and L.L.; investigation, R.L. and A.L.; resources, J.W. and A.L. and R.L.; data curation, R.L. and L.L.; writing-original draft preparation, R.L. and L.L.; writing—review and editing, S.N. and E.M. and J.W.; supervision, J.W.; project administration, J.W. and A.L. and R.L.; funding acquisition, R.L. and A.L. All authors have read and agreed to the published version of the manuscript.

Funding: This research was funded by National Natural Science Foundation of China, grant number 71904089; China Postdoctoral Science Foundation, grant number 2019M662392; Qingdao Postdoctoral Foundation.

Institutional Review Board Statement: The study was conducted according to the guidelines of the Declaration of Helsinki and approved by the Ethics Committee of Nanjing Medical University (protocol code Nanjing Medical University Ethical Audit (2020) Number 565 and 16 June 2020).

Informed Consent Statement: Informed consent was obtained from all subjects involved in the study.

Data Availability Statement: The data presented in this study are available on request from the corresponding author. The data are not publicly available due to multi-cooperation with Wuhan University, Shandong University and Nanjing Medical University. The corresponding author will facilitate a discussion with these three universities for data access on a reasonable request.

Acknowledgments: The authors thank reviewers for their constructive comments and thank all interviewers from the nine sample provinces for their contribution to the survey.

Conflicts of Interest: The authors declare no conflict of interest. 


\section{References}

1. Coronavirus Disease (COVID-2019) Situation Reports. Available online: https://www.who.int/emergencies/diseases/novelcoronavirus-2019/situation-reports (accessed on 20 March 2021).

2. The Associated Press and NORC Expectations for a COVID-19 Vaccine. Available online: https://apnorc.org/projects/ expectations-for-a-covid-19-vaccine/ (accessed on 19 April 2021).

3. COCONEL Group. A future vaccination campaign against COVID-19 at risk of vaccine hesitancy and politicisation. Lancet Infect. Dis. 2020, 20, 769-770. [CrossRef]

4. Yoda, T.; Katsuyama, H. Willingness to Receive COVID-19 Vaccination in Japan. Vaccines 2021, 9, 48. [CrossRef] [PubMed]

5. Frank, K.; Arim, R.G. Canadians' Willingness to Get a COVID-19 Vaccine: Group Differences and Reasons for Vaccine Hesitancy. 2020. Available online: https://www150.statcan.gc.ca/n1/pub/45-28-0001/2020001/article/00073-eng.htm (accessed on 26 March 2021).

6. Sherman, S.M.; Smith, L.E.; Sim, J.; Amlôt, R.; Cutts, M.; Dasch, H.; Rubin, G.J.; Sevdalis, N. COVID-19 vaccination intention in the UK: Results from the COVID-19 Vaccination Acceptability Study (CoVAccS), a nationally representative cross-sectional survey. Hum. Vaccines Immunother. 2020. [CrossRef]

7. Paul, E.; Steptoe, A.; Fancourt, D. Attitudes towards vaccines and intention to vaccinate against COVID-19: Implications for public health communications. Lancet Reg. Health. Eur. 2021, 1, 100012. [CrossRef]

8. Raftopoulos, V.; Iordanou, S.; Katsapi, A.; Dedoukou, X.; Maltezou, H.C. A comparative online survey on the intention to get COVID-19 vaccine between Greek and Cypriot healthcare personnel: Is the country a predictor? Hum. Vaccines Immunother. 2021. [CrossRef] [PubMed]

9. Gagneux-Brunon, A.; Detoc, M.; Bruel, S.; Tardy, B.; Rozaire, O.; Frappe, P.; Botelho-Nevers, E. Intention to get vaccinations against COVID-19 in French healthcare workers during the first pandemic wave: A cross sectional survey. J. Hosp. Infect. 2020, 108, 168-173. [CrossRef]

10. Bassett, S.F.; Prapavessis, H. A test of an adherence-enhancing adjunct to physiotherapy steeped in the protection motivation theory. Physiother. Theory Pract. 2011, 27, 360-372. [CrossRef] [PubMed]

11. Boer, H.; Emons, P.A.A. Accurate and inaccurate HIV transmission beliefs, stigmatizing and HIV protection motivation in northern Thailand. AIDS Care 2004, 16, 167-176. [CrossRef]

12. Fisher, A.; Bonner, C.; Biankin, A.V.; Juraskova, I. Factors influencing intention to undergo whole genome screening in future healthcare: A single-blind parallel-group randomised trial. Prev. Med. Int. J. Devoted Pract. Theory 2012, 55, 514-520. [CrossRef]

13. Prestwich, A.; Ayres, K.; Lawton, R. Crossing two types of implementation intentions with a protection motivation intervention for the reduction of saturated fat intake: A randomized trial. Soc. Sci. Med. 2008, 67, 1550-1558. [CrossRef]

14. Yan, Y.; Jacques-Tiura, A.J.; Chen, X.; Xie, N.; Chen, J.; Yang, N.; Gong, J.; MacDonell, K.K. Application of the Protection Motivation Theory in predicting cigarette smoking among adolescents in China. Addict. Behav. 2014, 39, 181-188. [CrossRef]

15. Bodenheimer, H.C.J.; Fulton, J.P.; Kramer, P.D. Acceptance of hepatitis B vaccine among hospital workers. Am. J. Public Health 1986, 76, 252-255. [CrossRef] [PubMed]

16. Rosenthal, S.L.; Kottenhahn, R.K.; Biro, F.M.; Succop, P.A. Hepatitis B vaccine acceptance among adolescents and their parents. J. Adolesc. Health 1995, 17, 248-254. [CrossRef]

17. Zimet, G.D.; Blythe, M.J.; Fortenberry, J.D. Vaccine characteristics and acceptability of HIV immunization among adolescents. Int. J. STD AIDS 2000, 11, 143-149. [CrossRef] [PubMed]

18. van der Veen, Y.J.; van Empelen, P.; Looman, C.W.; Richardus, J.H. Social-cognitive and socio-cultural predictors of hepatitis B virus-screening in Turkish migrants, the Netherlands. J. Immigr. Minor. Health 2014, 16, 811-821. [CrossRef] [PubMed]

19. Liu, C.; Nicholas, S.; Wang, J. The association between protection motivation and hepatitis b vaccination intention among migrant workers in Tianjin, China: A cross-sectional study. BMC Public Health 2020, 20, 1219. [CrossRef] [PubMed]

20. Ling, M.; Kothe, E.J.; Mullan, B.A. Predicting intention to receive a seasonal influenza vaccination using Protection Motivation Theory. Soc. Sci. Med. 2019, 233, 87-92. [CrossRef]

21. Camerini, A.-L.; Diviani, N.; Fadda, M.; Schulz, P.J. Using protection motivation theory to predict intention to adhere to official MMR vaccination recommendations in Switzerland. SSM Popul. Health 2019, 7, 100321. [CrossRef]

22. Rogers, R.W. A Protection Motivation Theory of Fear Appeals and Attitude Change1. J. Psychol. 1975, 91, 93-114. [CrossRef]

23. Floyd, D.L.; Prentice-dunn, S.; Rogers, R.W. A Meta-Analysis of Research on Protection Motivation Theory. J. Appl. Soc. Psychol. 2000, 30, 407. [CrossRef]

24. Bandura, A. Self-efficacy: Toward a unifying theory of behavioral change. Psychol. Rev. 1977, 84, 191-215. [CrossRef] [PubMed]

25. Barati, M.; Bashirian, S.; Jenabi, E.; Khazaei, S.; Karimi-Shahanjarini, A.; Zareian, S.; Rezapur-Shahkolai, F.; Moeini, B. Factors Associated with Preventive Behaviours of COVID-19 among Hospital Staff in Iran in 2020: An Application of the Protection Motivation Theory. J. Hosp. Infect. 2020, 105, 430-433. [CrossRef]

26. Prasetyo, Y.T.; Castillo, A.M.; Salonga, L.J.; Sia, J.A.; Seneta, J.A. Factors Affecting Perceived Effectiveness of COVID-19 Prevention Measures among Filipino during Enhanced Community Quarantine in Luzon, Philippines: Integrating Protection Motivation Theory and Extended Theory of Planned Behavior. Int. J. Infect. Dis. 2020, 99, 312-323. [CrossRef] [PubMed]

27. Wang, P.-W.; Ahorsu, D.K.; Lin, C.-Y.; Chen, I.-H.; Yen, C.-F.; Kuo, Y.-J.; Griffith, M.D.; Pakpour, A.H. Motivation to Have COVID-19 Vaccination Explained Using an Extended Protection Motivation Theory among University Students in China: The Role of Information Sources. Vaccines 2021, 9, 380. [CrossRef] [PubMed] 
28. COVID-19 Vaccination Free to Chinese Residents: Official. Available online: http://www.ecns.cn/news/2021-01-09/detailihafqmaz1834647.shtml (accessed on 5 February 2021).

29. The COVID-19 Vaccination Situation Report. Available online: http:/ /www.nhc.gov.cn/xcs/yqfkdt/202104/6f2444d14dce4ccda1 a53554feaa153a.shtml (accessed on 19 April 2021).

30. Lin, Y.; Hu, Z.; Zhao, Q.; Alias, H.; Danaee, M.; Wong, L.P. Understanding COVID-19 vaccine demand and hesitancy: A nationwide online survey in China. PLoS Negl. Trop. Dis. 2020, 14, e0008961. [CrossRef]

31. Wang, K.; Wong, E.L.-Y.; Ho, K.-F.; Cheung, A.W.-L.; Yau, P.S.-Y.; Dong, D.; Wong, S.Y.-S.; Yeoh, E.-K. Change of Willingness to Accept COVID-19 Vaccine and Reasons of Vaccine Hesitancy of Working People at Different Waves of Local Epidemic in Hong Kong, China: Repeated Cross-Sectional Surveys. Vaccines 2021, 9, 62. [CrossRef] [PubMed]

32. Alqudeimat, Y.; Alenezi, D.; AlHajri, B.; Alfouzan, H.; Almokhaizeem, Z.; Altamimi, S.; Almansouri, W.; Alzalzalah, S.; Ziyab, A. Acceptance of a COVID-19 Vaccine and its Related Determinants among the General Adult Population in Kuwait. Med. Princ. Pract. Int. J. Kuwait Univ. Health Sci. Cent. 2021. [CrossRef]

33. Harapan, H.; Wagner, A.L.; Yufika, A.; Winardi, W.; Anwar, S.; Gan, A.K.; Setiawan, A.M.; Rajamoorthy, Y.; Sofyan, H.; Vo, T.Q.; et al. Willingness-to-pay for a COVID-19 vaccine and its associated determinants in Indonesia. Hum. Vaccines Immunother. 2020, 16, 3074-3080. [CrossRef]

34. Mohammed, A.-M.; Kumar, P.B. Determinants of COVID-19 Vaccine Acceptance in Saudi Arabia: A Web-Based National Survey. J. Multidiscip. Healthc. 2020, 13, 1657-1663. [CrossRef]

35. Reiter, P.L.; Pennell, M.L.; Katz, M.L. Acceptability of a COVID-19 vaccine among adults in the United States: How many people would get vaccinated? Vaccine 2020, 38, 6500-6507. [CrossRef]

36. Willingness to pay for a COVID-19 vaccine high in Chile. Pharm. Outcomes News 2020, 858, 35. [CrossRef] [PubMed]

37. Sarasty, O.; Carpio, C.E.; Hudson, D.; Guerrero-Ochoa, P.A.; Borja, I. The demand for a COVID-19 vaccine in Ecuador. Vaccine 2020, 38, 8090-8098. [CrossRef] [PubMed]

38. Dodd, R.H.; Cvejic, E.; Bonner, C.; Pickles, K.; McCaffery, K.J. Willingness to vaccinate against COVID-19 in Australia. Lancet Infect. Dis. 2020. [CrossRef]

39. Nzaji, M.K.; Ngombe, L.K.; Mwamba, G.N.; Ndala, D.B.B.; Miema, J.M.; Lungoyo, C.L.; Mwimba, B.L.; Bene, A.C.M.; Musenga, E.M. Acceptability of Vaccination Against COVID-19 Among Healthcare Workers in the Democratic Republic of the Congo. Pragmatic Obs. Res. 2020, 11, 103-109. [CrossRef] [PubMed]

40. Leng, A.; Maitland, E.; Wang, S.; Nicholas, S.; Liu, R.; Wang, J. Individual preferences for COVID-19 vaccination in China. Vaccine 2021, 39, 247-254. [CrossRef]

41. Dong, D.; Xu, R.H.; Wong, E.L.-Y.; Hung, C.-T.; Feng, D.; Feng, Z.; Yeoh, E.-K.; Wong, S.Y.-S. Public preference for COVID-19 vaccines in China: A discrete choice experiment. Health Expect. Int. J. Public Particip. Health Care Health Policy 2020. [CrossRef]

42. Guidry, J.P.D.; Laestadius, L.I.; Vraga, E.K.; Miller, C.A.; Perrin, P.B.; Burton, C.W.; Ryan, M.; Fuemmeler, B.F.; Carlyle, K.E. Willingness to get the COVID-19 Vaccine with and without Emergency Use Authorization. Am. J. Infect. Control. 2020, 49, 137-142. [CrossRef]

43. Liu, R.; Li, Y.; Wangen, K.R. Analysis of hepatitis B vaccination behavior and vaccination willingness among migrant workers from rural China based on protection motivation theory. Hum. Vaccines Immunother. 2016, 12, 1155-1163. [CrossRef]

44. Jiang, S. Don't rush to deploy COVID-19 vaccines and drugs without sufficient safety guarantees. Nature 2020. [CrossRef] [PubMed]

45. Miyachi, T.; Takita, M.; Senoo, Y.; Yamamoto, K. Lower trust in national government links to no history of vaccination. Lancet 2020, 395, 31-32. [CrossRef]

46. Liu, Z.; Yang, J.Z. In the Wake of Scandals: How Media Use and Social Trust Influence Risk Perception and Vaccination Intention among Chinese Parents. Health Commun. 2020, 1-12. [CrossRef] [PubMed]

47. Malik, A.A.; McFadden, S.M.; Elharake, J.; Omer, S.B. Determinants of COVID-19 vaccine acceptance in the US. EClinicalMedicine 2020, 26, 100495. [CrossRef] [PubMed]

48. Verity, R.; Okell, L.C.; Dorigatti, I.; Winskill, P.; Whittaker, C.; Imai, N.; Cuomo-Dannenburg, G.; Thompson, H.; Walker, P.G.T.; $\mathrm{Fu}, \mathrm{H}$.; et al. Estimates of the severity of coronavirus disease 2019: A model-based analysis. Lancet Infect. Dis. 2020, 20, 669-677. [CrossRef]

49. Wong, L.P.; Alias, H.; Wong, P.F.; Lee, H.Y.; AbuBakar, S. The use of the health belief model to assess predictors of intent to receive the COVID-19 vaccine and willingness to pay. Hum. Vaccines Immunother. 2020, 16, 2204-2214. [CrossRef] [PubMed] 